\title{
Determinants of High Blood Pressure and Quality of Management in Three Regions of Benin
}

\author{
Mohamed Lamine Dramé1 ${ }^{*}$, Corine Houehanou ${ }^{2}$, Paulin Sogbohossou ${ }^{3}$, René Paré ${ }^{3}$, \\ Armand Ekambi ${ }^{3}$, Carmelle Mizéhoun-Adissoda ${ }^{2}$, Dismand Houinato ${ }^{2}$, Karel Gyselinck ${ }^{3}$, \\ Michael Marx ${ }^{4}$, Maria Rosáttrio Oliveira Martins' ${ }^{1}$, Paulo Ferrinho ${ }^{1}$ \\ ${ }^{1}$ GHTM, Instituto de Higiene e Medicina Tropical, Universidade Nova de Lisboa, Lisbon, Portugal \\ ${ }^{2}$ Faculty of Health Sciences, Laboratory of epidemiology of Chronic and Neurological Diseases (LEMACEN), Abomey-Calavi \\ University, Cotonou, Benin \\ ${ }^{3}$ Belgium Technical Cooperation-BTC, Cotonou, Benin \\ ${ }^{4}$ Heidelberg University, Heidelberg, Germany \\ Email: *mohdrame@yahoo.com
}

How to cite this paper: Dramé, M.L., Houehanou, C., Sogbohossou, P., Paré, R., Ekambi, A., Mizéhoun-Adissoda, C., Houinato, D., Gyselinck, K., Marx, M., Martins, M.R.O. and Ferrinho, P. (2018) Determinants of High Blood Pressure and Quality of Management in Three Regions of Benin. Open Journal of Epidemiology, 8, 14-28. https://doi.org/10.4236/ojepi.2018.81002

Received: October 2, 2017

Accepted: January 20, 2018

Published: January 23, 2018

Copyright $\odot 2018$ by authors and Scientific Research Publishing Inc. This work is licensed under the Creative Commons Attribution International License (CC BY 4.0).

http://creativecommons.org/licenses/by/4.0/

\begin{abstract}
Objective: The aim of this work was to determine the prevalence, associated factors and quality of high blood pressure (HBP) management in three regions of Benin in 2015. Methodology: This was a cross-sectional study, with two components. The first component included adults aged from 18 to 69 years, selected using a three-stage random sampling within the households. Data were collected thanks to the French version of the WHO STEPS instrument. Anthropometric data, including blood pressure, capillary fasting glucose and total cholesterol were measured according to standard procedures. The second component included Public Health Centers (PHC) selected by a random stratified multi-stage sampling. Data were collected on the structures and the processes of HBP management using the standardized tool for assessing the capacities of management of non-communicable diseases in peripheral health centers provided by the World Health Organization. Results: A total of 4816 participants were included in the first component. The mean age was $35.8 \pm 12.7$ years. The weighted prevalence of HBP was $27.9 \%$ (95\% Confidence Interval (CI) [25.6 - 30.2]). It was higher in the $60-69$ years compared to the lower age groups (Adjusted Odd-ratio $(\mathrm{ORa})=5$; 95\% CI $[3.9-6.5)]$ ). $\mathrm{HBP}$ was positively associated with urban residence (ORa $=1.26 ; 95 \% \mathrm{CI}[1.24$ - 1.28]), obesity $(\mathrm{ORa}=1.46 ; 95 \% \mathrm{CI}[1.43-1.50])$, hyperglycemia $(\mathrm{ORa}=$ 1.13; 95\% CI $[1.10-1.15)])$ and hypercholesterolemia $(\mathrm{ORa}=1.64 ; 95 \% \mathrm{CI}$ [1.59 - 1.70)]). A total of 27 PHC were included in the second component. Taking blood pressure and other anthropometric measurements was not routine in PHC. Several essential medicines were not available in the PHC. A low
\end{abstract}


level of community involvement in the management of HBP was noted. Conclusion: This study confirms the high prevalence of HBP and shows inadequacies in its management in the targeted PHC. More appropriate prevention and control measures for HBP should be implemented.

\section{Keywords}

High Blood Pressure, Determinants, Management, Benin

\section{Introduction}

High blood pressure (HBP) is one of the major risk factors for cardiovascular disease. It is one of the leading causes of death in the world where it caused about 10 million deaths and 218 million disability-adjusted life-years (DALYs) in 2015 [1] [2]. More than one third of the world adult populations suffer from HBP [3]. Sub-Saharan Africa is the region with the highest prevalence [3], ranging from $18 \%$ to $50 \%$ among adults [1] [4] [5] [6] [7]. The factors associated with HBP vary according to the epidemiological studies [5] [6] [7]. High-income countries have begun to reduce the prevalence of HBP in their populations through collective prevention measures and the provision of widely accessible diagnosis and treatment services. In sub-Saharan Africa, however, few people know their blood pressure status and few hypertensive patients are under treatment [8] [9] [10]. This may be due to inadequacies in the availability and accessibility of basic technologies and essential medicines in the health facilities, coupled with beliefs, low educational level and low economic status of some patients. Adequate and low-cost treatment of HBP patients is a challenge for health systems in sub-Saharan Africa. For World Health Organization (WHO) experts', attention should be paid to improve the quality of primary care at the peripheral level [11]. Among the nine targets of the global plan of action for the fight against noncommunicable diseases (NCDs) 2013-2020, there are three directly linked to the treatment of HBP.

Today, the world objectives called Sustainable Development Objectives (SDO) take into account NCDs [12]. However, the lack of reliable periodic epidemiological data would lead to the implementation of inappropriate interventions, leading not only to the failure to achieve the SDO but also to the wastage of already limited resources. In Benin, according to data from the national STEPS survey on the main risk factors (RF) of NCDs carried out in 2008, nearly $30 \%$ of the population aged 25 to 64 years had HBP [13]. This situation confirms the insufficiency in the prevention, diagnosis and treatment of HBP in Benin. Several surveys on the prevalence of HBP and its treatment are essential to guide the choice of prevention strategies.

The Benin-Belgian cooperation supports Benin for NCDs control interventions through the project called "PASS-SOUROU". A survey on NCDs risk factors prevalence and the quality of their management in the public health centers 
(PHC) was initiated in the PASS SOUROU intervention subterritory (PIS) for the development of a suitable response plan. The current work has used the data from this survey coordinated by its first author.

\section{Objectives}

The objective of this work was to determine the prevalence of HBP in 2015 among adults aged from 18 to 69 years living in the departments of Mono, Couffo and Donga, to identify associated factors and to assess the quality of HBP management in the PHC of these regions.

\section{Method}

\subsection{Study Framework}

The choice of the departments supported by Benin-Belgium cooperation (Mono, Couffo and Donga) based on some criteria as: high poverty rate, development needs not yet supported by Technical and Financial Partners and political considerations. The departments of Mono and Couffo are both located in the southwest of the Republic of Benin. The population of Benin has been estimated at about 10 million inhabitants in 2013 according to the Fourth General Population and Housing Census (GPHC4) [14]. The populations of Mono and Couffo were respectively 495,307 and 741,895 in 2013 [14]. These two departments are similar for the socio-cultural level with a predominance of the Adja ethnic group and similar dietary habits. As for the department of Donga, it is located in the north of Benin and occupies the southern zone of the former department of Atacora. Its population in 2013 was 542,605 inhabitants. At the socio-health and community level, these departments are faced with inadequate resources, including limited access to medical care, water and electricity.

The Beninese health system includes national hospitals all located in the town of Cotonou (central level), departmental hospitals (intermediate level), hospitals in the health zone and health centers (peripheral level). The territory is subdivided into 34 health zones. The health zone hospital is the first reference point for health centers, namely: private health centers, district health centers (DHC) and commune health centers (CHC). The DHC has a dispensary run by a nurse. The CHC is led by a medical doctor who also supervises the activities of the DHC of his commune.

\subsection{Study Design}

It was a cross-sectional study with a descriptive and analytical purpose. It included two components. The first part dealt with the prevalence and the associated factors to HBP and the second part evaluated the treatment of HBP.

\subsection{Study Population, Sampling, Data Collection and Analysis}

\section{Component I:}

The study population was constituted of all adults aged from 18 to 69 years 
living in the PIS for at least six months, were excluded from the study, all those who had not given their consent, those who had been given two unsuccessful visits, and anyone with a medical condition that prevented the administration of the questionnaire as: speech and language understanding problems, major mental problems.

Participants were selected using a three-stage random sampling technique. The sampling base constituted by all the Enumeration Areas was provided by the National Institute of Statistics and Economic Analysis (NISEA). At the first stage, 125 Enumeration Areas were selected by a simple random sampling with no delivery in each target area. At the second level, 20 households per Enumeration Area were drawn by a simple random sampling after counting all households in the Enumeration Area. The selection of the first two degrees was carried out in collaboration with the NISEA. At the last stage, one individual per household was selected according to the KISH method [15].

The sample size was calculated per department, taking into account the following parameters: a theoretical prevalence of $50 \%$ for NCDs risk factors, an alpha error risk of $5 \%$ and an accuracy of $6 \%$. The initial size obtained was then multiplied by 8 , considering 8 independent subpopulations according to the age groups and the sex. It was increased by $5 \%$ in anticipation of non-respondents. A sample size of 2499 subjects was thus predetermined for the department of Donga on the one hand and the same for the departments of the Mono/Couffo on the other hand, and a total of 4998 subjects to be investigated.

Data collection took place in the PIS from October 19th to December 19th, 2015. The French version of the WHO STEPS instrument was used. The tool has 3 parts: STEPS 1, 2, 3 [16]. Individual face-to-face interviews provided sociodemographic data, behavioral risk factors and data on the history of NCDs (STEP 1). Anthropometric measurements were then taken (STEP 2). The biological measurements were carried out the following morning after a fasting of at least 8 hours (STEP 3).

The weight of each participant was measured using an electronic scale of 0.1 $\mathrm{kg}$ (Model $753 \mathrm{E}$, Seca, Hamburg, Germany). The height was measured in a standing position with SECA gauge to within $0.1 \mathrm{~cm}$. The Body Mass Index (BMI) was calculated using the formula BMI $=$ weight $\left(\right.$ in $\mathrm{kg}$ ) $/ \mathrm{height}^{2}$ (in square meter). Waist circumference (WC) was measured at $0.1 \mathrm{~cm}$ using a non-elastic tape measure and WHO standards were used $(<102 \mathrm{~cm}$ for men, $<88 \mathrm{~cm}$ for women) [17]. The food evaluation was carried out using food models (standard glass, bowl, standard portions of fruits) to assess the food consumption of the subjected persons.

Blood pressure was measured three times in a row at 5-minute intervals while sitting in the left arm after a rest period of at least 15 minutes and using an electronic blood pressure device (Boso medicus, Germany). The average of the last two measures represented the systolic and diastolic blood pressures.

Blood glucose and cholesterol were measured on capillary blood using a read- 
er (Cardiocheck PA, PTS Diagnostics ${ }^{\mathrm{Tm}}$, USA), supplied by the WHO.

Data directly entered into the PDA (Personal Digital Assistant) was analyzed according to the STEPS recommendations using Epi info7 software (CDC Atlanta, USA). Pregnant women were excluded from the BMI data analysis. Data have been weighted according to sampling design. Qualitative variables were described as percentages with their $95 \%$ confidence intervals (CI). The quantitative variables were described as averages \pm standard deviations. Frequency comparison was done using either the Khi-2 test or the Fisher test. A multivariable logistic regression, using a step-by-step procedure, was performed to investigate the associated factors with HBP. The crude and adjusted odds ratios (OR) were calculated with their $95 \%$ CI. We used a significance degree of 0.05 .

\section{Component II:}

The population of quality care component was constituted of the PHC of the target areas. The PHC were selected using a stratified multi-stage random sampling. The Departments hospitals and health zone hospitals were systematically retained. In each of target department, $25 \%$ of the $\mathrm{CHC}$ were selected randomly. In each of the communes selected, $10 \%$ of the $\mathrm{DHC}$ were selected randomly.

The quality of care was evaluated through three dimensions: the structures, the care process and the results.

A team of two investigators visited each of the selected PHC. Data were collected through interviews with health center managers and health care providers, direct visits observation; review of records and/or care registers, and face-toface interviews with HBP patients. The standardized tool for assessing NCDs management capacity at the peripheral health center level developed by WHO was adapted for the study [18]. It included four sections on: the structures (availability of equipment, protocol of care, care providers, clinical and paraclinical examinations, essential medicines, community participation in the HBP management ...); the visit observation; the review of 12-months HBP patients' data concerning the care process (taking anthropometric measurements, prescribing biological exams, treatments, health and diet advice, setting up a follow-up appointment, blood pressure level during follow-up); and a questionnaire on the satisfaction of visited patients.

The number of observations and records has been reasonably defined. Ten patients present in each PHC at the time of the survey that were consulted for HBP, were randomly selected for the observation and the satisfaction survey.

The data analysis was made using the Epi Info 7 software. The qualitative variables were expressed as percentages. Missing data related to failure to keep files and care records books by health workers have not been able to evaluate the effectiveness of the HBP management in PHC.

\subsection{Ethical Considerations}

The study protocol received the agreement of the National Committee for Ethics in Health Research (NCEHR). The agreements of the departmental directors of 
health, the chief medical officers of the health zone, the directors of the hospitals, the responsibles of the health centers, the heads of districts, the heads of the home towns and villages, were obtained before the beginning of the investigation. The free, enlightened and written consent of each participant was required. The personal data of the participants were protected and the anonymity of the information collected was strictly respected during the investigation.

\section{Results}

\subsection{Component I}

\subsubsection{Sample Description}

A total of 4954 people aged from 18 to 69 years participated to the survey of which 4816 had valid blood pressure data. The demographic and socio-economic data are presented in Table 1 . There was a female predominance (58.3\%). The

Table 1. Socio-demographic characteristics of participants, STEPS Mono/Couffo-Donga, Benin 2015.

\begin{tabular}{|c|c|c|}
\hline Variables & Number $($ Total $=4816)$ & Percentage (\%) \\
\hline \multicolumn{3}{|l|}{ Age range (years) } \\
\hline $18-29$ & 1753 & 35.6 \\
\hline $30-44$ & 1879 & 38.3 \\
\hline $45-59$ & 958 & 19.5 \\
\hline $60-69$ & 326 & 6.6 \\
\hline \multicolumn{3}{|l|}{ Level of education } \\
\hline$\leq$ Primary school & 4417 & 89.9 \\
\hline$>$ Primary school & 499 & 10.1 \\
\hline \multicolumn{3}{|l|}{ Profession } \\
\hline Employee & 144 & 2.9 \\
\hline Independent worker & 3755 & 76.4 \\
\hline Unpaid & 1017 & 20.7 \\
\hline \multicolumn{3}{|l|}{ Place of residence } \\
\hline Urban & 1507 & 30.7 \\
\hline Rural & 3409 & 69.3 \\
\hline \multicolumn{3}{|l|}{ Department or region } \\
\hline Mono/Couffo (South) & 2438 & 49.6 \\
\hline Donga (North) & 2478 & 50.4 \\
\hline \multicolumn{3}{|l|}{ Marital Status } \\
\hline Never married & 655 & 13.3 \\
\hline Married & 3949 & 80.3 \\
\hline Separate & 312 & 6.4 \\
\hline \multicolumn{3}{|l|}{ Income (USD) } \\
\hline$<$ MGIS $^{*}$ & 4383 & 89.2 \\
\hline$\geq$ MGIS & 533 & 10.8 \\
\hline
\end{tabular}

*equivalent of the annual minimum guaranteed inter-professional minimum wage (MGIS) in Benin is 920 USD. 
mean age was $35.8 \pm 12.7$ years. The participants aged from 30 to 40 years were more numerous (38.3\%). The large majority of participants did not attend school and had an annual income below the Formal Minimum Annual Income (USD 960). The rural environment was more represented (69.3\%).

The information related to main NCDs risk factors is presented in Table 2. Nearly one-tenth of the participants were smokers. Approximately $3 \%$ of them consume abusively alcohol. Nearly a quarter of them had a low level of physical activity and more than one-tenth of them added salt to a cooked food. The majority of participants $(87.5 \%)$ had insufficient consumption of fruits and vegetables of less than 5 servings or $400 \mathrm{~g}$ per day. The prevalence of obesity was estimated at $6.7 \%$, that of hyperglycemia at $8.7 \%$ and that of hypercholesterolemia at $3.5 \%$.

\subsubsection{Prevalence of HBP and Associated Risk Factors}

The information related to the diagnosis, measurement and previous treatment of blood pressure is given in Table 3. More than three-quarters of participants never measured their blood pressure. Approximately 6\% of them had a history of HBP. From these, only $40 \%$ were under treatment the last fifteen days prior to the date of data collection.

The mean systolic blood pressure was $124.8 \pm 24.8 \mathrm{~mm} \mathrm{Hg}$ and that of the diastolic was $81.7 \pm 13.3 \mathrm{~mm} \mathrm{Hg}$.

The prevalence of HBP was $27.9 \%$ (95\% CI [25.6 - 30.2]) (see Table 3). It was higher in males compared to females (adjusted OR $=1.13$; 95\% CI $[1.11-1.15$ )]) (see Table 4).

Table 2. Weighted frequencies of behavioral and other metabolic risk factors of NCDs among participants, STEPS Mono/CouffoDonga, Benin 2015.

\begin{tabular}{|c|c|c|c|c|c|c|c|c|c|}
\hline \multirow{2}{*}{$\begin{array}{l}\text { Behavioral factors and other metabolic fac- } \\
\text { tors of CVD }\end{array}$} & \multicolumn{3}{|c|}{ Men } & \multicolumn{3}{|c|}{ Women } & \multicolumn{3}{|c|}{ Men and women } \\
\hline & $\mathrm{n}$ & $\%^{*}$ & IC 95\% & $\mathrm{n}$ & $\%^{*}$ & IC 95\% & $\mathrm{n}$ & $\%^{*}$ & IC 95\% \\
\hline Alcohol abuse ${ }^{* *}$ & 2121 & 4.3 & $2.6-6.0$ & 2833 & 1.6 & $0.9-2.4$ & 4954 & 3.0 & $2.0-4.0$ \\
\hline Alcohol excessive episodic drink ${ }^{\star * *}$ & 2121 & 17.3 & $14.3-20.2$ & 2833 & 6.3 & $4.4-8.1$ & 4954 & 12.0 & $10.0-14.0$ \\
\hline $\begin{array}{l}\text { Insufficient consumption of fruit and vegeta- } \\
\qquad \text { bles }^{* * * *}\end{array}$ & 2121 & 84.2 & $80.7-87.8$ & 2833 & 85.7 & $82.8-88.6$ & 4954 & 85.0 & $82.1-87.7$ \\
\hline Low physical activity ${ }^{\star * * * *}$ & 1965 & 18.3 & $14.3-23.7$ & 2607 & 27.2 & $21.2-33.2$ & 4572 & 22.9 & $18.2-27.7$ \\
\hline Adding salt to table. always or often & 2115 & 16.0 & $12.0-20.1$ & 2813 & 16.1 & $12.2-20.1$ & 4928 & 16.1 & $12.7-19.5$ \\
\hline Obesity $\left(\mathrm{IMC} \geq 30 \mathrm{~kg} / \mathrm{m}^{2}\right)$ & 2087 & 4.5 & $2.9-6.1$ & 2549 & 9.0 & $7.1-10.9$ & 4636 & 6.6 & $5.1-8.0$ \\
\hline $\begin{array}{l}\text { Capillary blood glucose } \geq 110 \mathrm{mg} / \mathrm{l} \text { or currently } \\
\text { under treatment for raised blood glucose }\end{array}$ & 2056 & 9.1 & $6.3-11.8$ & 2709 & 9.5 & $7.3-11.6$ & 4765 & 9.3 & $7.1-11.4$ \\
\hline $\begin{array}{c}\text { Total cholesterol } \geq 240 \mathrm{mg} / \mathrm{l} \text { or Currently under } \\
\text { treatment for raised blood cholesterol }\end{array}$ & 2065 & 2.6 & $1.5-3.6$ & 2759 & 5.2 & $3.8-6.6$ & 4814 & 3.9 & $3.0-4.7$ \\
\hline
\end{tabular}

n: subgroup number; ${ }^{*}$ Weighted frequency; ${ }^{* *}$ Abuse of alcohol past 30 days $\geq 40$ g per day in the men or $\geq 20$ g per day in the women; ${ }^{* * *} \geq 6$ standard alcohol drinks by occasion; ${ }^{* * *}<5$ servings of $80 \mathrm{~g}$ of fruits and vegetables consumed per day; ${ }^{* * *}<$ Equivalent to 600 MET/week; CVD: cardiovascular diseases. 
Table 3. Distribution of blood pressure data among the participants, STEPS Mono/Couffo-Donga, Benin 2015.

\begin{tabular}{|c|c|c|c|c|c|c|c|c|c|}
\hline \multirow{2}{*}{$\begin{array}{c}\text { History of blood pressure measure, of diagnosis and } \\
\text { treatment of high blood pressure and presence of } \\
\text { high blood pressure during the survey }\end{array}$} & \multicolumn{3}{|c|}{ Men } & \multicolumn{3}{|c|}{ Women } & \multicolumn{3}{|c|}{ Men and women } \\
\hline & $\mathrm{n}$ & $\%^{*}$ & IC 95\% & $\mathrm{n}$ & $\%^{*}$ & IC $95 \%$ & $\mathrm{n}$ & $\%^{*}$ & IC 95\% \\
\hline $\begin{array}{l}\text { Blood pressure measure and history of high blood } \\
\text { pressure }\end{array}$ & 2120 & & & 2831 & & & 4951 & & \\
\hline Never measured & 1641 & 75.9 & $72.1-79.7$ & 1797 & 63.5 & $59.1-67.8$ & 3438 & 69.9 & $66.4-73.4$ \\
\hline Measured, undiagnosed & 379 & 18.8 & $15.5-22.2$ & 838 & 29.3 & $25.5-33.1$ & 1212 & 23.9 & $20.9-26.9$ \\
\hline Diagnosis $>12$ months & 42 & 2.0 & $1.1-2.9$ & 64 & 2.0 & $1.5-2.7$ & 106 & 2.0 & $1.5-2.6$ \\
\hline Diagnosis $\leq 12$ months & 58 & 3.3 & $2.1-4.5$ & 132 & 5.2 & $3.9-6.5$ & 190 & 4.2 & $3.3-5.1$ \\
\hline Treatment of high blood pressure the last 15 days & 99 & & & 196 & & & 296 & & \\
\hline Under treatment & 35 & 35.1 & $20.6-49.6$ & 85 & 41.5 & $31.3-51.8$ & 120 & 38.7 & $28.7-48.7$ \\
\hline Without treatment & 65 & 65.7 & $50.4-79.4$ & 111 & 56.6 & $48.2-68.8$ & 176 & 59.7 & $51.3-71.3$ \\
\hline High blood pressure during the survey & 2116 & & & 2813 & & & 4929 & & \\
\hline Yes & 564 & 28.2 & $25.0-31.5$ & 760 & 27.5 & $24.8-30.2$ & 1324 & 27.9 & $25.6-30.2$ \\
\hline No & 1552 & 73.2 & $65.5-75.0$ & 2053 & 72.9 & $69.8-75.2$ & 3605 & 72.1 & $69.9-74.4$ \\
\hline
\end{tabular}

n: subgroup size; \%*: Weighted frequency according to survey plan; high Blood Pressure (BP) during the survey: systolic BP $\geq 140 \mathrm{~mm} \mathrm{Hg}$ ou diastolic BP $\geq$ $90 \mathrm{~mm} \mathrm{Hg}$ ) or under treatment of high blood pressure the last 15 days.

Table 4. Factors associated with high blood pressure, STEPS Mono/Couffo-Donga, Benin 2015.

\begin{tabular}{|c|c|c|c|c|c|c|}
\hline \multirow{3}{*}{ Variables } & \multicolumn{6}{|c|}{ High blood pressure (reference = "yes") } \\
\hline & \multicolumn{3}{|c|}{ Univariable analysis } & \multicolumn{3}{|c|}{ Multivariable analysis } \\
\hline & ORc & CI 95\% & $\mathrm{p}$ & ORa & CI 95\% & $\mathrm{p}$ \\
\hline \multicolumn{7}{|l|}{ Age (ref = $18-29$ years) } \\
\hline $30-44$ & 2.30 & {$[2.25-2.34]$} & $<0.001$ & 2.28 & {$[2.23-2.32]$} & $<0.001$ \\
\hline $45-59$ & 4.85 & {$[4.75-4.95]$} & $<0.001$ & 4.74 & {$[4.64-4.84]$} & $<0.001$ \\
\hline $60-69$ & 6.45 & {$[6.25-6.66]$} & $<0.001$ & 5.90 & {$[5.70-6.10]$} & $<0.001$ \\
\hline Sex female (ref = "male") & 1.04 & {$[1.03-1.06]$} & $<0.001$ & 1.13 & {$[1.11-1.15]$} & $<0.001$ \\
\hline Urban residence place (ref = "rural") & 1.36 & {$[1.34-1.38]$} & $<0.001$ & 1.26 & {$[1.24-1.28]$} & $<0.001$ \\
\hline South region (ref = "North region") & 1.51 & {$[1.49-1.54]$} & $<0.001$ & 1.56 & {$[1.53-1.59]$} & $<0.001$ \\
\hline Level of education $>$ Primary school ( ref = " $\leq$ Primary school") & 0.7 & {$[0.7-0.8]$} & $<0.001$ & 0.97 & {$[0.95-0.98]$} & $<0.001$ \\
\hline Obese (ref = "No") & 2.85 & {$[2.77-2.92]$} & $<0.001$ & 1.46 & {$[1.43-1.50]$} & $<0.001$ \\
\hline \multicolumn{7}{|l|}{ Professional occupation $(\mathrm{ref}=$ Employee $)$} \\
\hline Independent worker & 1.08 & {$[1.04-1.13]$} & $<0.001$ & 1.40 & {$[1.34-1.46]$} & $<0.001$ \\
\hline Unpaid & 0.77 & {$[0.74-0.80]$} & $<0.001$ & 1.31 & {$[1.24-1.36]$} & $<0.001$ \\
\hline Income $>$ MGIS** (ref $=$ “<MGIS”) & 1.24 & {$[1.22-1.27]$} & $<0.001$ & 1.09 & {$[1.07-1.11]$} & $<0.001$ \\
\hline Insufficient consumption of fruit and vegetables ( $\mathrm{ref}=$ "No") & 1.06 & {$[1.04-1.08]$} & $<0.001$ & 1.09 & {$[1.07-1.13]$} & $<0.001$ \\
\hline Physical activity < $600 \mathrm{MET} /$ week (ref = “ $\geq 600 \mathrm{MET} /$ week") & 1.45 & {$[1.43-1.48]$} & $<0.001$ & 1.31 & {$[1.28-1.33]$} & $<0.001$ \\
\hline $\begin{array}{l}\text { Capillary blood glucose } \geq 110 \mathrm{mg} / \mathrm{l} \text { or under treatment } \\
\text { (ref = "capillary blood glucose }<110 \mathrm{mg} / \mathrm{l} \text { ") }\end{array}$ & 1.61 & {$[1.57-1.65]$} & $<0.001$ & 1.13 & {$[1.10-1.15]$} & $<0.001$ \\
\hline $\begin{array}{c}\text { Total cholesterol } \geq 240 \mathrm{mg} / \mathrm{l} \text { or under treatment for } \\
\text { hypercholesterolemia }(\mathrm{ref}=\text { "Total cholesterol }<240 \mathrm{mg} / \mathrm{l} \text { ") }\end{array}$ & 2.39 & {$[2.30-2.47]$} & $<0.001$ & 1.64 & {$[1.59-1.70]$} & $<0.001$ \\
\hline Current Smokers, last 12 months (ref = "No") & 1.09 & {$[1.06-1.10]$} & $<0.001$ & & & \\
\hline Alcohol excessive episodic drink ${ }^{* * *}(\mathrm{ref}=$ "No") & 0.98 & {$[0.95-1]$} & 0.023 & & & \\
\hline
\end{tabular}

CI: Confidence Interval; ORc: crude Odd Ratio; ORa: OR adjusted with the other variables; ref = Reference category; ${ }^{\star *}$ equivalent to the annual minimum guaranteed inter-professional minimum wage (MGIS) in Benin $=920$ USD; ${ }^{\star * *} \geq 6$ standard units per occasion. 
The prevalence of HBP increased significantly with age. Thus, it was higher among the 60 - 69 age group compared to the lower age groups (adjusted OR = 6.45; 95\% CI [6.25 - 6.66)]) (see Table 4).

The prevalence of HBP was higher in urban than rural (adjusted OR = 1.26; 95\% CI [1.24 - 128)]). It was higher in the Southern region than in the North (adjusted OR $=1.56$; 95\% CI $[1.53-1.59)]$ ). HBP was positively associated with income (adjusted OR $=1.09 ; 95 \%$ CI [1.07 - 1.11]) while it was inversely associated to education (adjusted OR $=0.97 ; 95 \% \mathrm{CI},[0.95-0.98$ ) $]$ ).

It was significantly associated to "low physical activity practice" and "insufficient consumption of fruits and vegetables". The prevalence of HBP was higher among those who had low activity compared to those who did not (adjusted OR $=1.31 ;[1.28-1.33])$ and those who had insufficient consumption of fruits and vegetables compared to those who did not (adjusted OR $=1.09 ;[1.07-1.13]$ ).

The prevalence of HBP was higher among obese than non-obese (adjusted OR $=1.46 ; 95 \%$ CI [1.43 - 1.50]). It was higher in those who had hypercholesterolemia compared to those who did not (adjusted OR $=1.64 ;[1.59-1.70]$ ) and those with raised blood glucose compared to those did not have it (adjusted OR = 1.13; $[1.10-1.15])$.

\subsection{Component II}

A total of 27 PHC was included in the survey. There were $15 \mathrm{DHC}, 5 \mathrm{CHC}$ and 7 hospitals. A total of 46 people was interviewed (15 in the DHC, 10 in the CHC and 21 in the hospitals) to obtain information on the structures dimension of the PHC. A total of 494 records or registry data (253 in the DHC, 100 in the CHC and 141 in the hospitals) were counted. A total of 51 patients were asked about their satisfaction, including 48 in hospitals.

In the $\mathrm{DHC}$, the number of nurses varied between 1 and 2. In $\mathrm{CHC}$, the number of nurses varied between 2 and 4; one physician was employed by CHC. In hospitals, the number of nurses varied between 10 and 31, and those of general practitioners between 2 and 4 . One departmental hospital on both visited used a cardiologist and the latter was on partial time. There was no nephrologist in the hospitals visited.

The mean consultation fee per level is generally around 0.4 USD for nurses, 2.5 USD for general practitioners and 4.5 USD for specialist physicians. Visit, care and medication are fully paid by patients in all $\mathrm{CHC}$, all hospitals, and 93.3\% of DHC. In the month prior to data collection, the median number of visits recorded for HBP was 1 (interquartile range: 0 - 9) in DHC, 6 (interquartile range: 3 - 8) in CHC and 17 (interquartile range: 9 - 32) in hospitals. The number of consultations for all causes in the same period was 289 (interquartile range: 11 - 988) in DHC, 483 (interquartile range: 322 - 589) in CHC and 144 (interquartile range: 49 - 507) in hospitals.

Less than one-fifth of the health workers in the PHC have received specific, recent, continuing professional training on HBP (Table 5). 
Table 5. Evaluation of the quality of high blood pressure management, STEPS Mono/Couffo-Donga, Benin 2015.

\begin{tabular}{|c|c|c|c|c|}
\hline \multirow{2}{*}{ Dimensions and components } & \multirow{2}{*}{ Categories } & \multicolumn{3}{|c|}{ DHC $(\mathrm{N}=15) \mathrm{CHC}(\mathrm{N}=5) \mathrm{ZH} / \mathrm{DH}(\mathrm{N}=7)$} \\
\hline & & $\mathrm{n}(\%)$ & $\mathrm{n}(\%)$ & $\mathrm{n}(\%)$ \\
\hline Structures: human resources & Minimum trained qualified human resources in NCDs & $2(13.3)$ & $1(20.0)$ & $1(14.3)$ \\
\hline \multirow[t]{5}{*}{ Structures: materials } & High blood pressure treatment protocol & $3(20.0)$ & $2(40.0)$ & $6(85.7)$ \\
\hline & Material for IEC & $1(6.7)$ & $0(0.0)$ & $1(14.2)$ \\
\hline & Functional Kit (Ribbon, bathroom scale, measuring rod) & $13(86.7)$ & $4(80.0)$ & $7(100.0)$ \\
\hline & Functional Stethoscope & $14(93.3)$ & $5(100.0)$ & $7(100.0)$ \\
\hline & Functional Blood Pressure Monitor & $12(80.0)$ & $5(100.0)$ & $7(100.0)$ \\
\hline \multirow[t]{2}{*}{ Structures: community actions } & Awareness of the population & $0(00.0)$ & $0(00.0)$ & $1(14.3)$ \\
\hline & Patient Support Group & $0(00.0)$ & $0(00.0)$ & $0(00.0)$ \\
\hline \multicolumn{5}{|l|}{ Structures: complementary exams } \\
\hline & Blood glucose & -- & $4(80.0)$ & $7(100.0)$ \\
\hline & Creatininemia & -- & $3(60.0)$ & $7(100.0)$ \\
\hline & Cholesterolemia & -- & $2(40.0)$ & $6(85.7)$ \\
\hline & EKG & -- & -- & $4(57.1)$ \\
\hline & Proteinuria/24h & -- & -- & $4(57.1)$ \\
\hline & Eye examen & -- & -- & $5(71.4)$ \\
\hline \multirow[t]{4}{*}{ Structures: essential drugs } & Thiazide (Hydrochlorothiazide) & $13(86.7)$ & $4(80.0)$ & $5(71.4)$ \\
\hline & Central antihypertensor (Methyldopa) & $15(100.0)$ & $5(100.0)$ & $7(100.0)$ \\
\hline & Conversion enzyme inhibitors (Captopril) & -- & $2(40.0)$ & $2(28.6)$ \\
\hline & Calcic channel blockers (Long acting Nifedipine, Amlodipine) & -- & $5(100.0)$ & $6(85.7)$ \\
\hline \multirow[t]{5}{*}{ Clinical process } & Systematic blood pressure measurement & $14(93.3)$ & $3(60.0)$ & $6(85.7)$ \\
\hline & Systematic weight measurement & $12(80.0)$ & $3(60.0)$ & $5(71.4)$ \\
\hline & Systematic height recording & $2(13.3)$ & $0(14.3)$ & $5(71.4)$ \\
\hline & At least one follow-up visit per patient ${ }^{*}$ & $4(26.3)$ & $2(40.0)$ & $0(0.0)$ \\
\hline & At least two follow-up visits per patient* & 0.0 & 0.0 & $0(0.0)$ \\
\hline
\end{tabular}

DHC: district health center, CHC: communal health center, ZH/DH: zone hospital/departmental hospital; ${ }^{*}$ retrospective (from review register and records, registered visit); IEC: information, education and communication.

Basic materials for blood pressure measurement and for obesity screening were available in most of the PHC (Table 5). Inversely, care protocols and education materials for the prevention of cardiovascular diseases were scarcely available in these PHC, especially in the DHC (Table 5). Blood glucose, creatininemia and blood cholesterol levels were not performed in DHC. Electrocardiogram recording was not available neither in the DHC nor in CHC; it was not available in all hospitals either. Essential medicines for the treatment of HBP, such as calcium channels blockers (nifedipine, amlodipine ...) and angiotensinconverting enzyme inhibitors (captopril, enalapril ...), were not available in DHC. The most widely available essential medicine was "hydrochlorothiazide" 
(thiazide diuretic) and "methyldopa" (central antihypertensive drug). A single hospital among the $27 \mathrm{PHC}$ was conducting population sensitization or patient support groups. Very few PHC had systematically recorded in the records and/ or registries at least one follow-up visit per hypertensive patient (Table 5); none of the hypertensive patients had had two follow-up visits.

In hospitals where hypertensive patients' visits were observed, dietary advice was only provided in $51.2 \%$ of the 48 patients. The consultation period was between 30 minutes and 2 hours for about half (54.2\%) of the patients. However, the majority of patients (88.5\%) were generally satisfied with the reception and explanations provided by the physician regarding the HBP and prescribed treatment.

\section{Discussion}

The study population was relatively young with an average age of 35 years. About one-tenth smoked tobacco. More than one-fifth of the participants were sedentary. Less than one fifth consumed a sufficient quantity of fruits and vegetables. One in four participants had high blood pressure or a history of HBP under treatment and was classified HBP patient. The prevalence of HBP was similar to that observed in the national STEPS 2008 survey (27.9\%) [12]. It is similar to what was observed in the STEPS survey in Uganda in 2015 with adults (26.4\%) [5]. Lower prevalences were observed in Togo in 2010 (19\%) among those aged 15 - 64 years and in Burkina-Faso in 2013 among adults aged 25 - 64 years (17.6\%) [19]. However, it is significantly lower than that reported in South Africa in the province of Limpopo by Ntuli (41\%) out of a size of 1281 people aged 15 years and over [7].

The prevalence of HBP increased with age as classically reported in the literature. Urban residents had higher prevalence of HBP compared to those living in rural areas. These findings are consistent with the results of the national STEPS 2008 survey [12] as well as those reported by other African authors [8] [20] [21]. This difference in risk was explained in Benin by the higher incidence of poor diet, lack of physical activity and inadequate consumption of fruit and vegetables in the cities compared to the countryside [22]. This explanation still seems valid; further analysis of the database study will confirm this.

The prevalence of HBP was higher among men than women. This result differs from the data from the STEPS survey in Benin in 2008, during which there was no association between HBP and the gender. We also noticed that obese people had a higher prevalence of HBP than non-obese, which was noted by other studies [23] [24] [25] [26]. Similarly, in our study, HBP was positively associated with total hypercholesterolemia and hyperglycemia; this finding is not surprising since HBP is often associated with other risk factors for cardiovascular disease. The results observed by N'Guetta et al. in Côte D'Ivoire on outpatients followed for HBP confirm this thesis because they observed a metabolic syndrome in about half of the hypertensive patients in their study [27]. 
Regarding the quality of the HBP management, the availability of basic materials for screening of HBP was generally good, while that of other risk factors basic devices, essential medicines and complication detection materials were lower. The proportion of health workers who received recent continuing professional training on HBP was very low. The measurement of blood pressure and/or its recording during visits was not systematic. In addition, fewer patients have benefited of follow-up visits in the same PHC. Health workers should be periodically trained in the diagnosis and treatment of HBP and standardized care protocols should be available. It was noted that PHC neither carry out activities involving the communities, notably mass sensitization nor the setting up of patient support groups. This lack of community involvement may justify the low demand for HBP diagnosis and care.

The problem of low availability of essential drugs and basic diagnostic tests such as blood glucose is not specific to Benin. According to the studies led in several developing countries, availability of essential drugs and basic diagnostic tests for chronic disease management is low in public health centers, especially in sub-Saharan Africa [28] [29] [30]. Adapted measures should be taken in Benin to improve the availability of basic technologies and essential medicines necessary for the adequate treatment of HBP in both public and private centers [31]. Simple and inexpensive technologies (electronic and solar readers) as well as generic drugs for low-cost treatment of HBP should be chosen. Particular emphasis should be placed in sub-Saharan Africa on the support of peripheral health centers. Since peripheral health centers are the most accessible to the population, it seems necessary to reorganize them for an adequate minimal treatment of HBP by starting with public structures. This approach would reduce the number of HBP complications among patients and the reference to higher-level hospitals.

\section{Strengths and Limits}

The study is one of the first in Benin and sub-Saharan Africa to evaluate both the prevalence and the management of HBP. The results of this study constitute the baseline data for the local response plan against HBP evaluation. The first part of the study was conducted using the STEPS methodology recommended by the WHO for the surveillance of NCDs risk factors, thus ensuring comparability with other studies from STEPS surveys. A three-stage random sampling technique was applied for the selection of people, a number of subjects required were predetermined and a response rate greater than $90 \%$ was obtained. A representative sample was thus constituted.

The collection of behavioral variables was based on statements; information biases, in particular social desirability, may have been introduced, which may underestimate the proportions observed. The blood pressure standards used correspond to the WHO criteria [19]. However, the operational definition used for HBP may lead to an overestimation of the prevalence of HBP, as it is based 
on point measurements.

Regarding the quality of HBP management, in particular the follow-up visits of hypertensive patients may have been underestimated by default in recording data because their collection was based on the retrospective files. In addition, patient satisfaction in hospitals may have been overestimated as it is based on reports collected within the hospital. Additionally, the study concerned only three departments among twelve. The results are not applicable to all the public health centers in Benin. The management of HBP in a department like Cotonou (economic capital of Benin) could be better.

\section{Conclusion}

This work allows updating the data on the HBP in general population in Benin, particularly in the area studied. It confirms earlier findings on the importance of HBP in Benin. They also show the low availability of essential medicines and supplementary balance sheets for adequate minimal management of $\mathrm{HBP}$ in peripheral PHC. It is necessary to carry out more efficient actions in Benin, in particular in the SIP, for better prevention and adequate and low-cost treatment of HBP in these populations.

\section{Acknowledgements}

The authors thank Dr Guédou Fernand for his contribution to the paper, Mr. Maurice Sinha for the English translation, National Program of Non-Communicable Diseases/Health Ministry of Benin, PASS SOUROU Program of BeninBelgium technical cooperation.

\section{Conflict of Interest}

The authors declare no conflict of interest.

\section{References}

[1] Wang, H., Naghavi, M., Allen, C., Barber, R.M., Bhutta, Z.A., Carter, A., et al. (2016) Global, Regional, and National Life Expectancy, All-Cause Mortality, and Cause-Specific Mortality for 249 Causes of Death, 1980-2015: A Systematic Analysis for the Global Burden of Disease Study 2015. The Lancet, 388, 1459-1544. https://doi.org/10.1016/S0140-6736(16)31012-1

[2] GBD 2015 DALYs and HALE Collaborators (2016) Global, Regional, and National Disability-Adjusted Life-Years (DALYs) for 315 Diseases and Injuries and Healthy Life Expectancy (HALE), 1990-2015: A Systematic Analysis for the Global Burden of Disease Study 2015. Lancet, 388, 1603-1658. https://doi.org/10.1016/S0140-6736(16)31460-X

[3] Organisation mondiale de la Santé, Bureau régional de l'Afrique (2014) La santé des populations: Les mesures efficaces-Le Rapport sur la santé dans la Région africaine 2014. OMS Afrique, 202.

[4] Guwatudde, D., Nankya-Mutyoba, J., Kalyesubula, R., Laurence, C., Adebamowo, C., Ajayi, I., et al. (2015) The Burden of Hypertension in Sub-Saharan Africa: A Four-Country cross Sectional Study. BMC Public Health, 15, 1211. 
https://doi.org/10.1186/s12889-015-2546-Z

[5] Guwatudde, D., Mutungi, G., Wesonga, R., Kajjura, R., Kasule, H., Muwonge, J., et al. (2015) The Epidemiology of Hypertension in Uganda: Findings from the $\mathrm{Na}$ tional Non-Communicable Diseases Risk Factor Survey. PLoS ONE, 10, Article ID: e0138991. https://doi.org/10.1371/journal.pone.0138991

[6] Muhamedhussein, M.S., Nagri, Z.I. and Manji, K.P. (2016) Prevalence, Risk Factors, Awareness, and Treatment and Control of Hypertension in Mafia Island, Tanzania. International Journal of Hypertension, 2016. https://doi.org/10.1155/2016/1281384

[7] Ntuli, S.T., Maimela, E., Alberts, M., Choma, S. and Dikotope, S. (2015) Prevalence and Associated Risk Factors of Hypertension amongst Adults in a Rural Community of Limpopo Province, South Africa. African Journal of Primary Health Care \& Family Medicine, 7, 847.

[8] Damasceno, A., Azevedo, A., Silva-Matos, C., Prista, A., Diogo, D. and Lunet, N. (2009) Hypertension Prevalence, Awareness, Treatment, and Control in Mozambique: Urban/Rural Gap during Epidemiological Transition. Hypertension, 54, 7783. https://doi.org/10.1161/HypertensionAHA.109.132423

[9] Camara, A., Baldé, N.M., Diakité, M., Sylla, D., Baldé, E.H., Kengne, A.P., et al. (2016) High Prevalence, Low Awareness, Treatment and Control Rates of Hypertension in Guinea: Results from a Population-Based STEPS Survey. Journal of Human Hypertension, 30, 237-244. https://doi.org/10.1038/jhh.2015.92

[10] Kayima, J., Wanyenze, R.K., Katamba, A., Leontsini, E. and Nuwaha, F. (2013) Hypertension Awareness, Treatment and Control in Africa: A Systematic Review. BMC Cardiovascular Disorders, 13, 54. https://doi.org/10.1186/1471-2261-13-54

[11] United Nations Organization. Sustainable Development Goals. United Nations Organization, New York. http://www.un.org/sustainabledevelopment/fr

[12] Saksena, P., Xu, K., Elovainio, R. and Perrot, J. (2012) Utilization and Expenditure at Public and Private Facilities in 39 Low-Income Countries. Tropical Medicine \& International Health: $T M \& I H, 17,23-35$. https://doi.org/10.1111/j.1365-3156.2011.02894.x

[13] Houinato, D.S., Gbary, A.R., Houehanou, Y.C., Djrolo, F., Amoussou, M., SegnonAgueh, J., et al. (2012) Prevalence of Hypertension and Associated Risk Factors in Benin. Revue D’épidémiologie Et De Santé Publique, 60, 95-102. https://doi.org/10.1016/j.respe.2011.09.010

[14] Institut National de la Statistique et de l'Analyse Economique (2015) RGPH4 : Que retenir des effectifs de 2013. INSAE, Cotonou, 33. http://www.insae-bj.org/recensement-population.html

[15] Berthier, C., Caron, N. and Neros, B. (1998) La méthode de Kish: les problèmes de réalisation du tirage et de son extrapolation. Série Méth Stat, n89810, INSEE, Paris.

[16] World Health Organisation. Manual STEPS. World Health Organization. http://www.who.int/chp/steps/manual/fr/

[17] World Health Organization (2000) Obesity: Preventing and Managing the Global Epidemic. WHO Technical Reports No. 894, World Health Organization, Geneva.

[18] World Health Organization. Tools for Implementing WHO PEN (Package of Essential Noncommunicable Disease Interventions). World Health Organization. http://www.who.int/ncds/management/pen_tools/en

[19] World Health Organization. STEPS Country Reports. World Health Organization. http://www.who.int/chp/steps/reports/en/ 
[20] Fezeu, L., Kengne, A.P., Balkau, B., Awah, P.K. and Mbanya, J.C. (2010) Ten-Year Change in Blood Pressure Levels and Prevalence of Hypertension in Urban and Rural Cameroon. Journal of Epidemiology and Community Health, 64, 360-365. https://doi.org/10.1136/jech.2008.086355

[21] Agyemang, C. (2006) Rural and Urban Differences in Blood Pressure and Hypertension in Ghana, West Africa. Public Health, 120, 525-533. https://doi.org/10.1016/j.puhe.2006.02.002

[22] Houehanou, Y.C.N., Lacroix, P., Mizehoun, G.C., Preux, P.-M., Marin, B. and Houinato, D.S. (2015) Magnitude of Cardiovascular Risk Factors in Rural and Urban Areas in Benin: Findings from a Nationwide Steps Survey. PLoS ONE, 10, e0126441. https://doi.org/10.1371/journal.pone.0126441

[23] Maimela, E., Alberts, M., Modjadji, S.E.P., Choma, S.S.R., Dikotope, S.A., Ntuli, T.S., et al. (2016) The Prevalence and Determinants of Chronic Non-Communicable Disease Risk Factors amongst Adults in the Dikgale Health Demographic and Surveillance System (HDSS) Site, Limpopo Province of South Africa. PLoS ONE, 11, e0147926. https://doi.org/10.1371/journal.pone.0147926

[24] Bosu, W.K. (2016) Determinants of Mean Blood Pressure and Hypertension among Workers in West Africa. International Journal of Hypertension, 2016, Article ID: 3192149. https://doi.org/10.1155/2016/3192149

[25] Patel, S.A., Ali, M.K., Alam, D., Yan, L.L., Levitt, N.S., Bernabe-Ortiz, A., et al. (2016) Obesity and Its Relation with Diabetes and Hypertension: A Cross-Sectional Study across 4 Geographical Regions. Global Heart, 11, 71-79. https://doi.org/10.1016/j.gheart.2016.01.003

[26] Ononamadu, C.J., Ezekwesili, C.N., Onyeukwu, O.F., Umeoguaju, U.F., Ezeigwe, O. C. and Ihegboro, G.O. (2017) Comparative Analysis of Anthropometric Indices of Obesity as Correlates and Potential Predictors of Risk for Hypertension and Prehypertension in a Population in Nigeria. Cardiovascular Journal of Africa, 28, 92 99. https://doi.org/10.5830/CVJA-2016-061

[27] N'Guetta, R., Yao, H., Brou, I., Ekou, A., Do, P., Angoran, I., et al. (2016) Prevalence and Characteristics of Metabolic Syndrome among Hypertensive Patients in Abidjan. Annales de Cardiologie et d'angéiologie, 65, 131-135. https://doi.org/10.1016/j.ancard.2016.04.009

[28] Cameron, A., Roubos, I., Ewen, M., Mantel-Teeuwisse, A.K., Leufkens, H.G.M. and Laing, R.O. (2011) Differences in the Availability of Medicines For chronic and Acute Conditions in the Public and Private Sectors of Developing Countries. Bulletin of the World Health Organization, 89, 412-421. https://doi.org/10.2471/BLT.10.084327

[29] Jingi, A.M., Noubiap, J.J.N., Ewane Onana, A., Nansseu, J.R.N., Wang, B., Kingue, S., et al. (2014) Access to Diagnostic Tests and Essential Medicines for Cardiovascular Diseases and Diabetes Care: Cost, Availability and Affordability in the West Region of Cameroon. PLoS ONE, 9, e111812. https://doi.org/10.1371/journal.pone.0111812

[30] Robertson, J., Macé, C., Forte, G., de Joncheere, K. and Beran, D. (2015) Medicines Availability for Non-Communicable Diseases: The Case for Standardized Monitoring. Globalization and Health, 11, 18. https://doi.org/10.1186/s12992-015-0105-0

[31] McGuire, H. and Weigl, B.H. (2014) Medical Devices and Diagnostics for Cardiovascular Diseases in Low-Resource Settings. Journal of Cardiovascular Translational Research, 7, 737-748. https://doi.org/10.1007/s12265-014-9591-3 